\title{
The influence of diet and diabetes on stearoyl Coenzyme A desaturase (EC 1.14.99.5) activity and fatty acid composition in rat tissues
}

\author{
BY NANCY A. WORCESTER, K. R. BRUCKDORFER, \\ T. HALLINAN, A. J. WILKINS AND JANE A. MANN \\ Department of Biochemistry and Chemïstry, \\ Royal Free Hospital School of Medicine, 8 Hunter Street, London $W C_{\text {I }} N_{\text {I }} B P$ \\ AND J. YUDKIN \\ Queen Elizabeth College, Campden Hill Road, London $W 8 \quad 7 A H$
}

(Received 8 May 1978 - Accepted 28 July 1978)

\begin{abstract}
I. Rats were given low-fat diets for $3 \mathrm{~d}$ in which the carbohydrate source was starch. The livers of animals given the fructose or sucrose had increased hepatic activities of the fatty acid synthetase and stearoyl CoA desaturase ( $E C$ 1.14.99.5) enzyme complexes: in those given fructose there was a lower activity of the enzymes in adipose tissue.

2. Similar results were obtained in rats given fructose diets for $30 \mathrm{~d}$, but in animals which had previously been made diabetic with streptozotocin, the activities were lower. The dietary treatment made little difference to the fatty acid profiles of the tissue lipids. The diabetic condition on the other hand produced considerable changes in fatty acid profile.

3. With diets containing approximately $200 \mathrm{~g}$ fat $/ \mathrm{kg}$ in the form of butter or of polyunsaturated margarine, the tissue lipids from rats given sucrose had less linoleic acid than those from rats given starch. In addition, there was the expected difference between the rats given butter or margarine. The results are discussed in relation to the current literature.
\end{abstract}

In many tissues the $\Delta 9$ desaturase enzyme complex converts saturated fatty acyl coenzyme A esters to the monounsaturated form. In rats this enzyme is increased by saturated fat in the diet and decreased by fasting (Inkpen et al. 1969), so that monounsaturated fatty acids occur in high concentration in most lipid fractions. Whereas there is considerable evidence that dietary fructose or sucrose increased hepatic fatty acid synthesis and associated enzymes (Bruckdorfer et al. I972; Cohen, et al. 1972; Romsos \& Leveille, 1974), the effects of different dietary carbohydrates on desaturation have been much less studied. Early work indicated that feeding sucrose to rabbits or human volunteers resulted in changes in the fatty acid profile of tissue lipids, primarily a decrease in the linoleic acid content and a concomitant increase in the monounsaturated fatty acids (Macdonald, 1962; Macdonald \& Braithwaite, 1964). Similar changes were shown in the biliary phosphatidylcholines of human subjects given sucrose, although in that study the dietary controls were not adequate (Alling $e t$ al. 1973). In more recent experiments with rats, dietary fructose produced greater activity in hepatic stearoyl CoA desaturase (EC I.14.99.5) both in vivo and in vitro than did dietary glucose (Mercuri et al. 1974). These experiments were short term and the rats were given the glucose and fructose diets for different periods of time, giving rise to the possibility that the differences were due to 'overshoot effects' as a result of diet change. No comparison of the more usual dietary carbohydrates starch and sucrose was made in that study.

It has also been shown that fructose and sucrose have opposite effect on adipose tissue, in that they decrease lipogenesis and lipogenic enzyme activities (Bruckdorfer et al., 1972; Romsos \& Leveille, 1974). For this reason we examined the effects of sucrose and fructose 
on desaturation in adipose tissue as well as in the liver. De Tomas et al. (1973) found that desaturase activity was reduced in rats made diabetic with streptozotocin, suggesting that the enzyme was controlled by insulin as was suggested in the earlier work of Gellhorn \& Benjamin (1964), who used alloxan diabetic rats. We therefore investigated the effects of fructose in rats treated with strepozotocin.

A simple assay system has been devised for stearoyl CoA desaturase (Johnson \& Gurr, I97I) in which the crude microsomal preparation is incubated with $\left[9, \mathrm{IO}^{3} \mathrm{H}_{2}(n)\right]$ stearic acid dispersions, which results in the release of tritium-labelled water in proportion to the enzyme activity. One of the difficulties with this procedure is the preparation of consistent dispersions of stearic acid. In this paper we describe a modification of this method, in which stearic acid was co-dispersed with phosphatidylcholine by ultrasonication.

The fatty acid composition of tissue lipids in long-term experiments with fructose and sucrose, sometimes with fat-rich diets, were determined.

\section{MATERIALS AND METHODS}

Animals and diets

Male Sprague-Dawley rats (Charles River (UK) Ltd, Margate, Kent) weighing I00-I Io g were given standard laboratory diet $4 \mathrm{IB}$ (Dixon Ltd, Ware, Herts.) for I week before feeding experimental diets $a d l i b$. for 3 or $30 \mathrm{~d}$ or 6 months with free access to water. Some rats were made diabetic by injection of streptozotocin (Upjohn Ltd, Kalamazoo, USA) into the tail vein in a dose of $65 \mathrm{mg} / \mathrm{kg}$ body-weight. Glycosuria was detected with 'Clinistix' (Ames Co., Slough, Bucks.) and the animals given the experimental diets after I week. The rats were randomized into groups which were given diets differing by the type of carbohydrate, and in one experiment also by the nature of the fat.

The low-fat diet contained $(\mathrm{g} / \mathrm{kg}): 700$ fructose, glucose, sucrose or maize starch, 190 casein (Casumen; Unigate Food Ltd, Trowbridge, Wilts.), 20 maize oil, 30 cellulose, 20 vitamin mix and 40 mineral mix. The vitamin mix contained cellulose, choline bitartrate and vitamin concentrate in the proportion of $1760: 180: 60.2$ by weight. The vitamin concentrate contained (g): ascorbic acid $\mathrm{I} 5$, nicotinic acid $\mathrm{I} 2$, vitamin $\mathrm{B}_{12}$ mix Io (I $\mathrm{mg}$ cyanocobalamin $/ \mathrm{g}$ ), calcium pantothenate 8 , thiamine hydrochloride 2 , riboflavin 2 , pyridoxine 2 , folic acid I, biotin 0.29, menadione 0.2, Rovimix E 2560 , Rovimix $A_{3}$ 500/100 2.4, Rovimix A-500 2.8 (Roche Products Ltd, Welwyn, Herts). The mineral mix contained: CaHPO $.2 \mathrm{H}_{2} \mathrm{O}, \mathrm{CaCO}_{3}, \mathrm{KCl}, \mathrm{Na}_{2} \mathrm{HPO}_{4}, \mathrm{MgSO}_{4} \cdot 7 \mathrm{H}_{2} \mathrm{O}$, trace minerals in the proportions I644:820:740:498.5:46.5, by weight. The trace minerals were $\mathrm{MnSO}_{4} \cdot 4 \mathrm{H}_{2} \mathrm{O}$, ferric citrate, $\mathrm{CuSO}_{4} \cdot 5 \mathrm{H}_{2} \mathrm{O}, \mathrm{ZnCO}_{3}$ and $\mathrm{KIO}_{3}$ in the proportions $59 \cdot 4: 43 \cdot 5: 5.9: 7.5: 0 \cdot 25$, by weight.

The fat-rich diets contained $(\mathrm{g} / \mathrm{kg}) 550$ sucrose or starch, 200 butter or polyunsaturated margarine, $\mathrm{I} 60$ casein and the same ingredients as in the low-fat diet but excluding maize oil. Animals on these diets were fed for a period of 6 months.

At the end of the experiments the animals were killed by carbon dioxide anaesthesia and in some instances exsanguinated from the heart, Livers and epididymal adipose tissues were also excised, washed in cold isotonic saline ( $9 \mathrm{~g}$ sodium chloride/l), blotted and weighed. Portions of the tissues were frozen for the later determination of lipid fatty acid composition.

Other tissue samples were weighed fresh and homogenized in $0.25 \mathrm{M}$-sucrose and centrifuged at $10000 \mathrm{~g}$ for $10 \mathrm{~min}$ at $4^{\circ}$ in an MSE I 8 centrifuge (MSE Scientific Instruments, Crawley, Sussex). The supernatant fraction was then centrifuged for $\mathrm{I}$ h at $4^{\circ}$ in an MSE 50 Ultracentrifuge at $104000 \mathrm{~g}$ and the microsomal pellet and supernatant fraction retained. The microsomal pellet was either frozen at $-21^{\circ}$ or used directly by resuspension in $0.25 \mathrm{M}$-sucrose ( $\mathrm{pH}_{7.4}$ ) and diluted to $2.5 \mathrm{mg}$ protein/ $/ \mathrm{ml}$ (Lowry et al. 1951). 


\section{Fatty acid synthetase}

The activity was assayed on the $104000 \mathrm{~g}$ supernatant fraction as described in a previous paper (Bruckdorfer et al. 1972). Malonyl CoA, acetyl CoA, NADPH and bovine serum albumin (fatty acid free) were purchased from Sigma Chemical Co., London.

\section{Stearoyl CoA desaturase}

The method adopted was based on that described by Johnson \& Gurr (1971) in which the elimination of tritium into water from $\left[9, \mathrm{IO}^{3} \mathrm{H}_{2}(n)\right]$ stearic acid (Radiochemical Centre, Amersham, Bucks.) was used to measure activity in crude microsomal preparations. The main difficulty with this method was an inconsistency in the dispersion of stearic acid in an aqueous environment. This can be improved with sodium hydroxide or detergents, but consistent and reproducible values were obtained by dispersion of the stearic acid in egg phosphatidylcholine liposomes.

Preparation of liposomes. $0.6 \mu \mathrm{mol}(100 \mu \mathrm{c})\left[9, \mathrm{IO}^{3} \mathrm{H}_{2}(n)\right]$ stearic acid and $6.0 \mu \mathrm{mol}$ egg phosphatidylcholine (Lipid Products, Redhill, Surrey) were dried under nitrogen in a vial which was sealed after addition of $2 \mathrm{ml} 0.02 \mathrm{M}$-hepes buffer, $\mathrm{pH} \mathrm{7.4}$. The vial was sonicated for $4 \mathrm{~min}$ in a sonication bath (Rapidis Ultrasonic Disintegrator $20 \mathrm{KHz}$, I 50 watt; Ultrasonics Ltd, Shipley). Short periods of sonication were found to be adequate for dispersion of the stearic acid and 'background' radioactivity due to tritium exchange increased with longer sonication. This gave enough substrate for approximately twenty assays. Dispersions were prepared fresh each day to reduce tritium exchange with the aqueous medium.

Incubation with microsomes. Each assay mixture was prepared as follows: $0.1 \mathrm{ml}$ stearic acid dispersion $(5 \mu \mathrm{C})$ was pipetted into a small stoppered tube and mixed with other solutions to give a volume of $0.25 \mathrm{ml}$, containing concentrations of $3.3 \mathrm{mM}-\mathrm{Mg}^{2+}, 0.134 \mathrm{~mm}-$ coenzyme A, I6 mM-ATP and $0.934 \mathrm{~mm}-\mathrm{NADH}$. To this ice-cooled mixture $0.2 \mathrm{ml}$ microsomal suspension (usually $0.5 \mathrm{mg}$ protein) was added, mixed for $5 \mathrm{~s}$ and then incubated in a water bath at $37^{\circ}$ for $5 \mathrm{~min}$.

After 10 min the reaction was halted with $0.05 \mathrm{ml} 40 \mathrm{~mm}$-potassium cyanide containing $28.8 \mathrm{~g}$ bovine serum albumin/1, which both inhibit the enzyme through the cyanide-sensitive component of the electron transport chain and bind the stearic acid substrate. After $30 \mathrm{~s}$, I $\mathrm{ml}$ trichloroacetic acid ( $100 \mathrm{~g} / \mathrm{l}$ ) was added, precipitating protein and bound-lipid and leaving tritiated water due to desaturation in the aqueous medium. After $10 \mathrm{~min}$ in ice the tubes were centrifuged for $10 \mathrm{~min}$ at $3000 \mathrm{~g}$. Supernantant fraction (I ml) was transferred to a scintillation vial and dispersed in $\mathrm{I} 0 \mathrm{ml}$ of a mixture $(2: \mathrm{I}$, by vol) of scintillation fluid (6 g 2(4'-t-butylphenyl)-5-(4"-biphenyl)-I,3,4,-oxadiazole and $0 \cdot \mathrm{I} g$ methyl I,4 di 2(4 methyl-5 phenyloxazole)-benzene in I 1 toluene: Koch Light Laboratories Ltd., Colnbrook, Bucks.) - Triton X-IOo (Koch Light Ltd), and radioactivity counted on a Packard Tricarb scintillation spectrometer (Model 3385). Each assay was performed in triplicate. Addition of internal standards to a number of assays showed a very consistent efficiency of counting from sample to sample $(35 \cdot 3 \%)$.

Control assays were performed in duplicate for each sample. This was achieved by addition of the cyanide before the incubation, which inhibited enzyme activity but not the tritium exchange between stearic acid and water. In most instances the 'background' counts were less than $25 \%$ of the total counts. After subtraction of the 'control' counts, the activity was expressed as counts/min per mg microsomal protein per min. The absolute activity of the enzyme could not be readily calculated because of the mixed substrates used and existence of isotope effects (Johnson \& Gurr, 197I). Nevertheless these authors have shown that oleate formation is proportional to tritiated water release. 


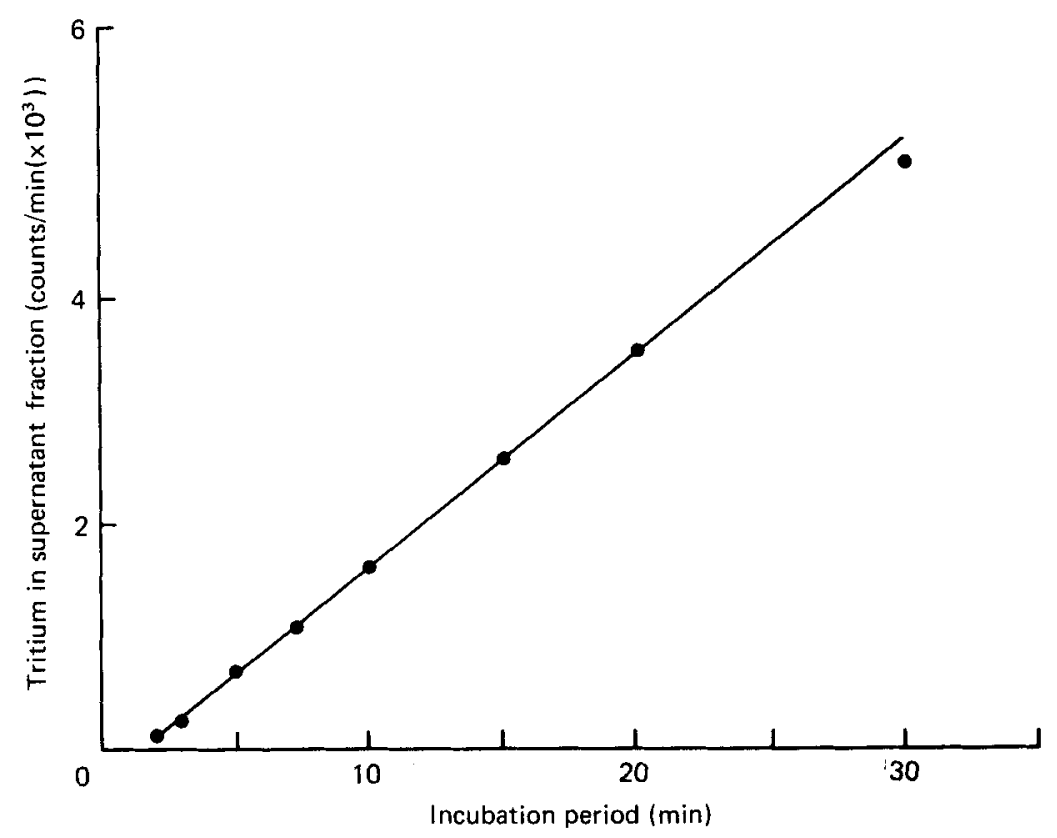

Fig. I. Reliability studies on stearoyl CoA desaturase activity. Liposomes containing $0.03 \mu \mathrm{mol}$ $(5 \mu \mathrm{c})$ of $\left[9, \mathrm{IO}^{3} \mathrm{H}_{2}(n)\right]$ stearic acid and $0.3 \mu \mathrm{mol}$ egg phosphatidylcholine in hepes buffer $\mathrm{pH} 7 \cdot 4$ were incubated for $5-30$ min with rat liver microsomes ( $0.5 \mathrm{mg}$ protein) in a medium containing $\mathrm{Mg}^{2+}$, coenzyme A, ATP and NADH to permit formation of stearoyl COA and its desaturation. The reaction was stopped by addition of potassium cyanide and bovine serum albumin and the ${ }^{8} \mathrm{H}$ eliminated during desaturation as ${ }^{3} \mathrm{H}_{2} \mathrm{O}$ was counted in the supernatant fraction obtained after addition of trichloroacetic acid and centrifugation (for details, see p. 24I). A blank value was obtained from incubations which were identical except that $\mathrm{KCN}$ was added at the beginning. The points are an average of triplicate measurements.

\section{Insulin}

Plasma insulin concentrations were determined by the radioimmunoassay procedure of Hales \& Randle (1963). Materials were obtained from the Radiochemical Centre, Amersham, Bucks. Values are expressed in equivalents of porcine insulin.

\section{Lipid analysis}

Lipids in the plasma, adipose tissue and liver were extracted by the method of Folch et al. (1957), and the major fractions containing fatty acid separated by thin-layer chromatography (Skipski et al. 1968). Methyl esters of the fatty acids contained in the lipid fractions were prepared with methanolic hydrogen chloride or sodium methoxide as described by Christie (1973). The fatty acid composition was determined using a Pye 104 gas chromatograph with dual flame ionization detection (Pye-Unicam Ltd, Cambridge), operating at $190^{\circ}$ with an argon flow of $50 \mathrm{ml} / \mathrm{min}$ through $1.5 \mathrm{~m}$ glass columns containing $100 \mathrm{~g}$ polyethyleneglycoladipate $/ \mathrm{kg}$ I00 - I20 Mesh Diatomite CAW support (Pye Unicam Ltd). Peak areas were determined directly by a computing integrator DP 88 (Pye Unicam Ltd). 


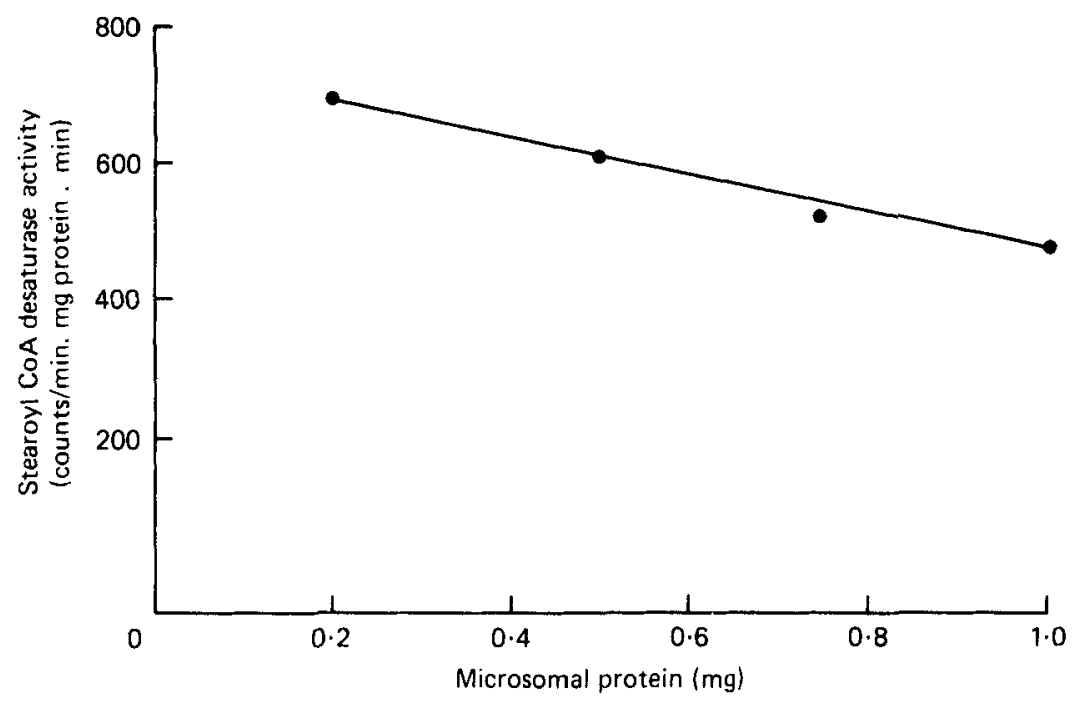

Fig. 2. Stearoyl coenzyme A desaturase activity (counts/min per mg protein per min) at a range of microsomal protein concentrations (for details of procedures, see p.24I). The activity was expressed as ${ }^{3} \mathrm{H}$ label released per $\mathrm{mg}$ microsomal protein. The points are an average of triplicate measurements.

\section{RESULTS}

\section{Stearoyl CoA desaturase assay}

Experiments were performed to demonstrate the reliability of this assay procedure. With a fixed quantity of microsomes, $0.5 \mathrm{mg}$ protein $/ \mathrm{ml}$, a linear time-course for activity was obtained for at least $30 \mathrm{~min}$ (Fig. I) and a $10 \mathrm{~min}$ interval was used for further assays. A large excess of substrate was used and the activity appeared to vary only slightly in the range $0.2-1.0 \mathrm{mg}$ microsomal protein (Fig. 2). Nevertheless in all assays the microsomal protein was diluted to give a final concentration of $0.5 \mathrm{mg}$ protein $/ \mathrm{ml}$. Reproducible results were obtained in triplicated assays on the same microsomes under identical conditions, giving a value with the range $\pm 4 \%$ of the mean.

\section{Short-term experiments}

Rats were fed on a low-fat diet containing fructose or glucose for $3 \mathrm{~d}$ as described by Mercuri et al. (1974). As observed in earlier work (Bruckdorfer et al. 1972), the liver weight was greater in the animals fed on fructose compared to those fed on glucose (Table $\mathrm{I}(a)$ ). In the liver the activities of both fatty acid synthetase and stearoyl CoA desaturase were significantly increased by feeding fructose. In adipose tissue, fatty acid synthetase was lower in the fructose group as previously observed (Bruckdorfer et al. 1972). Stearoyl CoA desaturase activity was also lower in rats fed on fructose, but to a smaller extent.

With diets containing sucrose and starch, differences were again observed. In the $3 \mathrm{~d}$ of this experiment, sucrose did not produce the greater liver weight seen in more prolonged experiments (Bruckdorfer et al. 1972). Hepatic fatty acid synthetase activities showed a greater difference between the starch and sucrose groups than did the activities of stearoyl CoA desaturase; for both enzymes the differences were statistically significant (Table I $(b)$ ). In the adipose tissue only fatty acid synthetase activity was significantly lower in the sucrose group. 


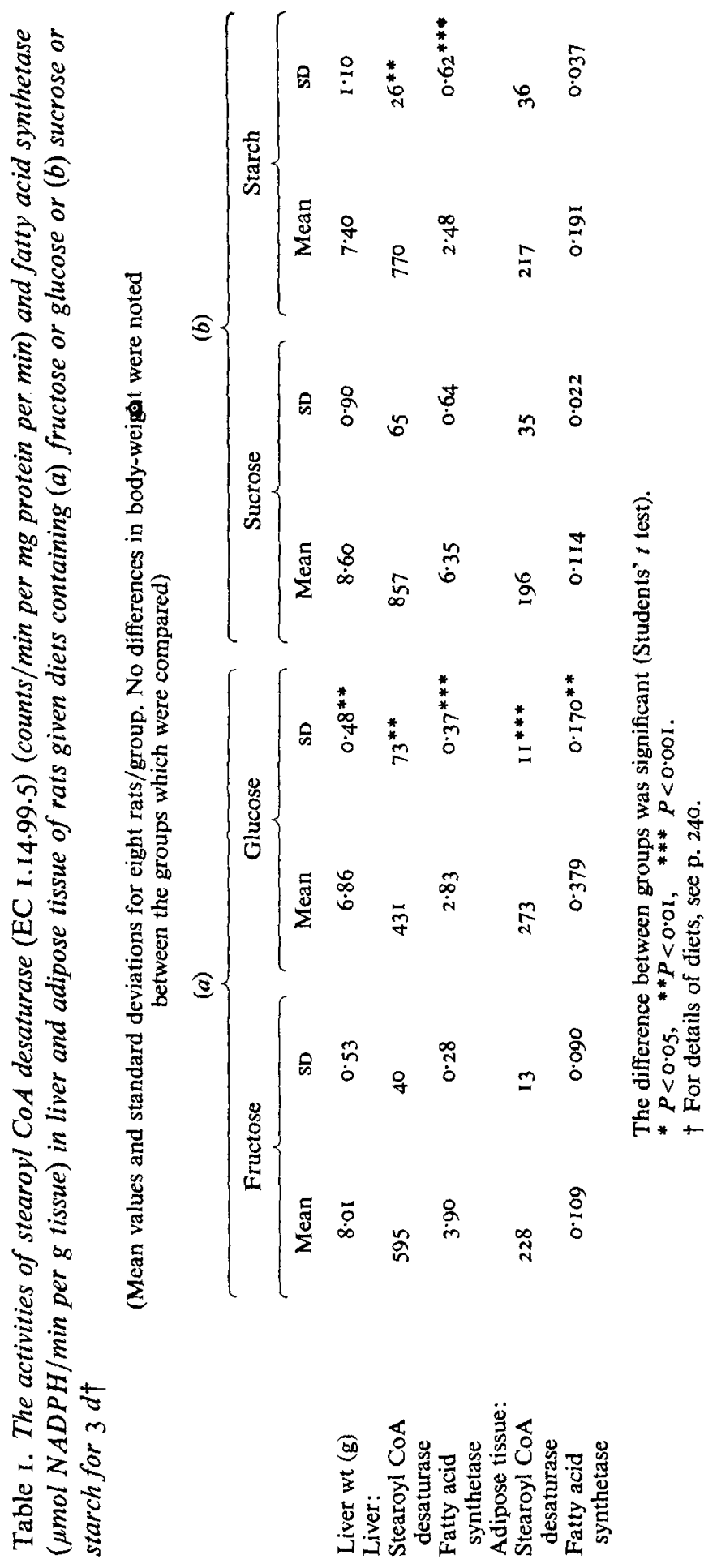




\section{Fructose and diabetes}

The comparison of the effects of low-fat fructose and glucose diets was also made after a period of $30 \mathrm{~d}$. These diets were given to animals made diabetic with streptozotocin. Fructose again produced heavier livers in both normal and diabetic rats (Table 2). As in the shortterm experiment, fructose increased the activities of hepatic fatty acid synthetase and stearoyl $\mathrm{CoA}$ desaturase in normal rats and also in diabetic rats. Diabetes decreased these enzyme activities in rats fed on both diets (Table 2). The adipose tissue mass of diabetic rats was too small for enzyme activity to be measured. A greater difference between fructose- and glucosefed rats was observed for fatty acid synthetase than in the $3 \mathrm{~d}$ experiment, but the decrease in desaturase activity in fructose-fed rats was less, although still significant.

In the same experiment very low concentrations of plasma insulin levels were detected in the diabetic rats, but no significant differences were caused by the different dietary treatments. When the values for all groups were combined a positive correlation, $r 0.73(P<0.001)$, was found between plasma insulin and liver fatty acid synthetase activities, but not between insulin and any other measurements. A correlation also exists between hepatic fatty acid synthetase and stearoyl CoA desaturase activity both in liver, $r 0.53(P<0.01)$, and also in adipose tissue $r 0.53(P<0.02)$. Similar correlations were observed in the $3 \mathrm{~d}$ experiment between the two enzymes in liver, $r 0.64(P<0.01)$, and in adipose tissue $r 0.59(P<0.01)$.

\section{Fatty acid profiles}

Analyses were made of the tissue fatty acid profiles of rats fed on the low-fat diets for $30 \mathrm{~d}$ and of those fed fat-rich diets for 6 months. The effects of the carbohydrate component of the diets were greater in the long-term experiment.

Only slight differences occurred in the fatty acid compositions of the phospholipid and triglyceride fractions of plasma and liver lipids obtained from rats fed on fructose and glucose diets (Tables 3 and 4). This was also true of the cholesteryl ester fatty acids and the total lipid profiles from adipose tissue (not shown). The values for the ratios, 16:0: I6: I fatty acids and 18:0: 18: I fatty acids were also not significantly different. As may be expected in animals where the metabolism of lipids has been profoundly disturbed, fatty acid composition of the plasma and liver lipids of the lean diabetic rats were very different, irrespective of the dietary carbohydrate, with a much larger content of polyunsaturated fatty acids, especially linoleic acid. In all instances, with the exception of plasma phospholipids, there was an increase in the value for $18: 0: 18: 1$ fatty acids indicating impaired desaturation in diabetes (Tables 3 and 4). The value for 16:0:16:I fatty acids was not measurable in all fractions because of the very low content of $16: 1$, especially in diabetic rats. In liver triglycerides, no significant change in the value for I6:0:I6: I was observed, but in liver phospholipids and plasma triglycerides the virtual disappearance of the I6:I (palmitoleic) fatty acid indicated a low level of desaturation of 16:0 in diabetes. In cholesteryl ester fractions a higher 16:0: I6: I value was found in diabetic rats (not shown).

In the long-term experiment with high levels of fat in the diet a clear effect of dietary carbohydrate and fat was shown. The linoleic acid contents of the diets differed considerably, since butter contained $25 \mathrm{~g}$ linoleic acid $/ \mathrm{kg}$ and margarine $560 \mathrm{~g}$ linoleic acid $/ \mathrm{kg}$. Starch also has a small unextractable fraction of free linoleic acid so that the four diets contained slight unequal amounts of linoleic acid, even when the same dietary fat was used: ( $\mathrm{g} / \mathrm{kg}$ diet) sucrose-butter $5^{\circ} \mathrm{O}$, sucrose-margarine I I $1 \cdot 8$, starch-butter $6 \cdot 5$, and starchmargarine II 3.3 .

Despite their presence in butter only traces of short- and medium-chain fatty acids were found in the tissues of rats which had been fasted overnight and then killed. The most striking difference between the groups of rats was the expected large amounts of linoleic 


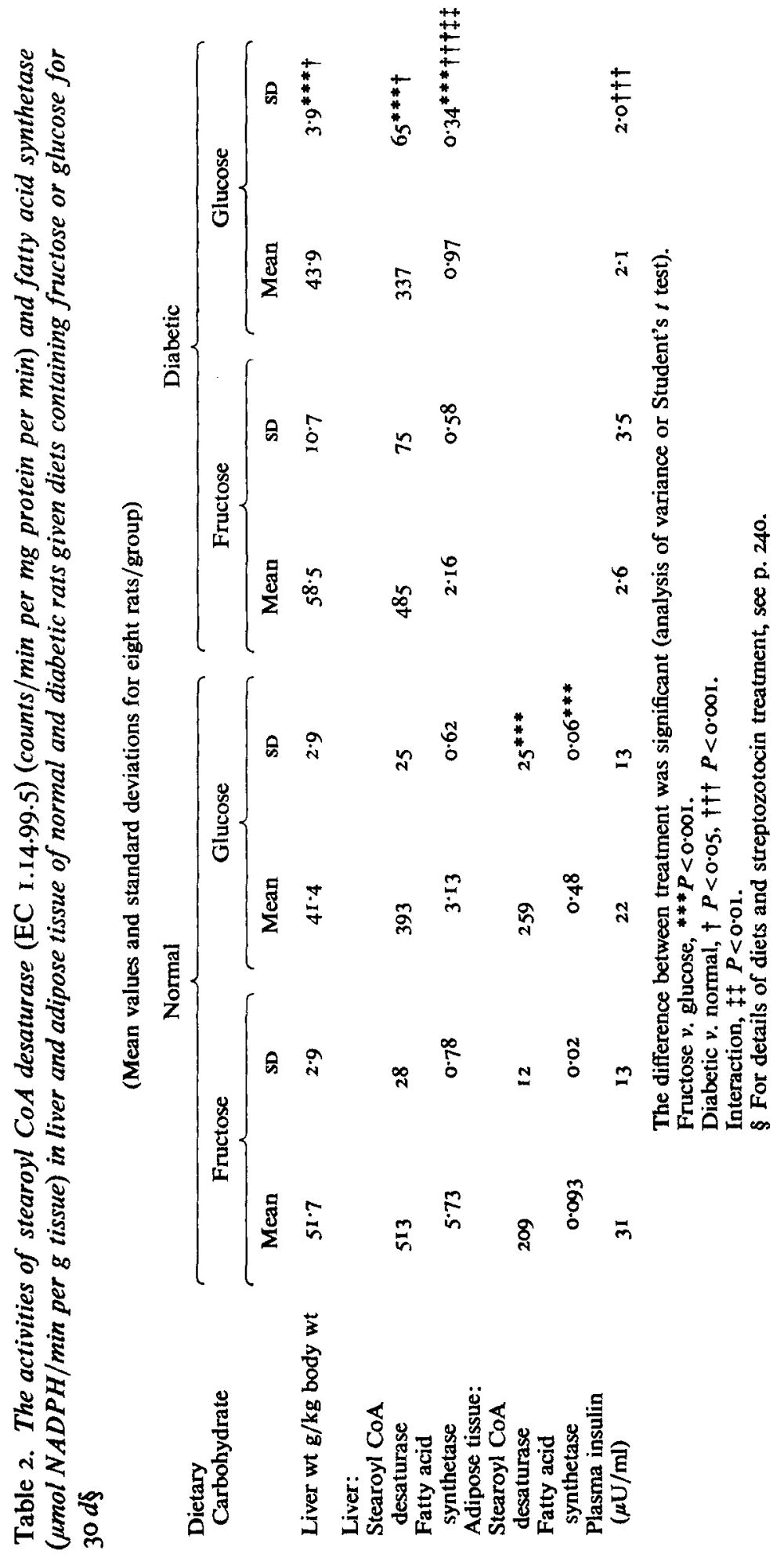




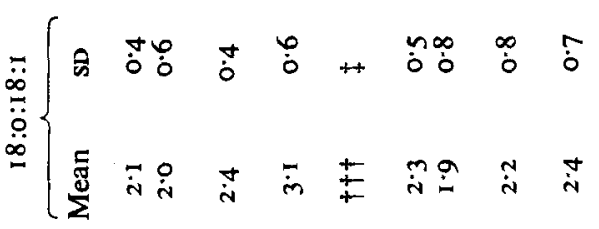

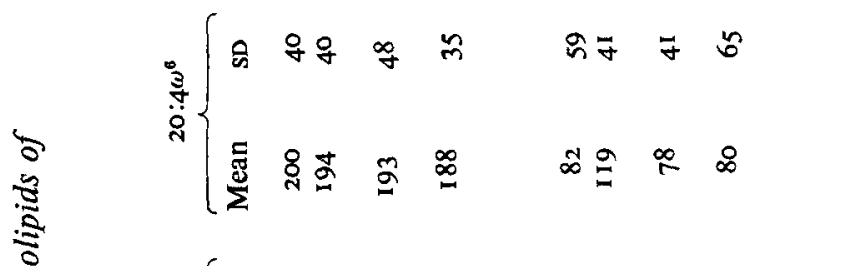

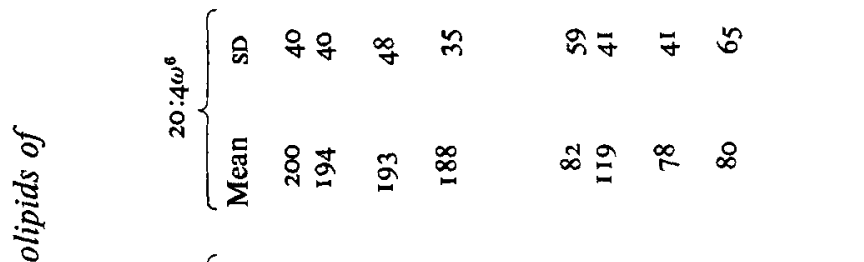

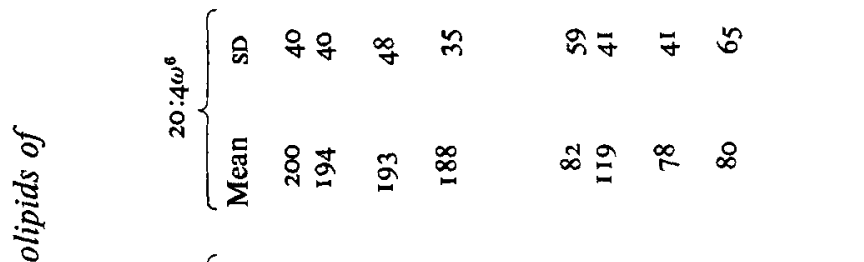

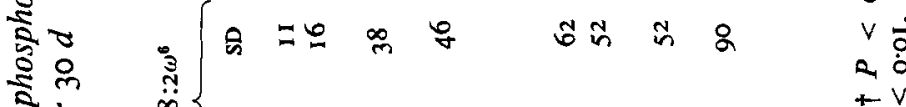

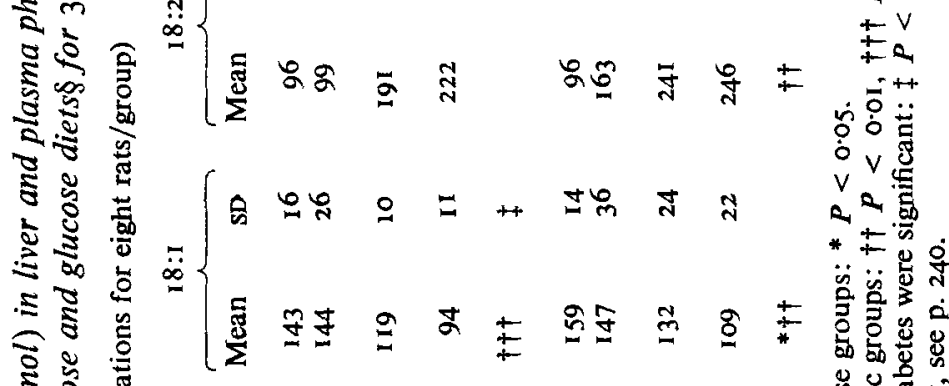

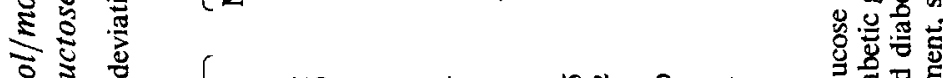

通范

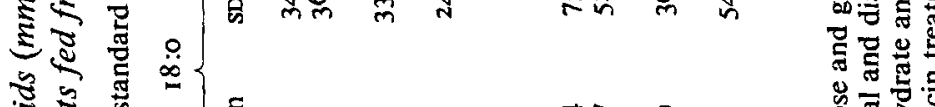

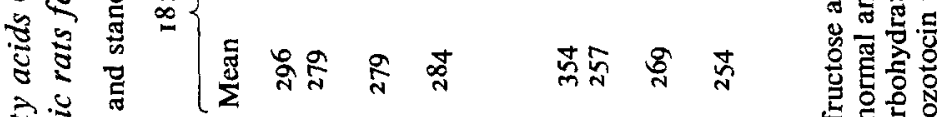

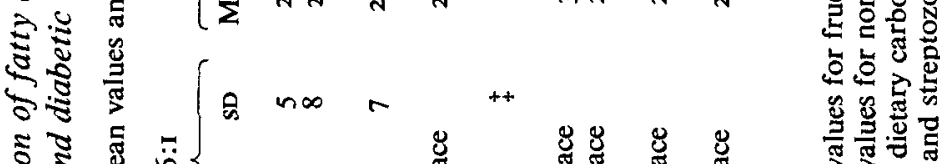

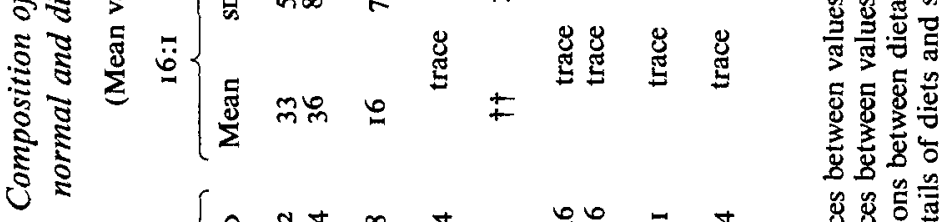

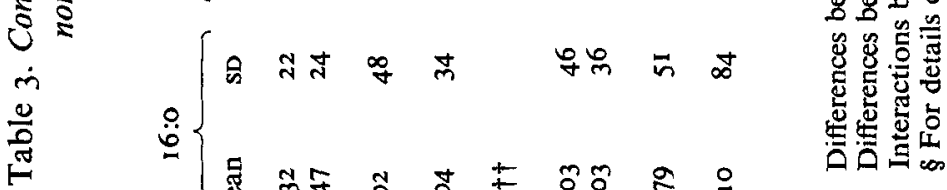

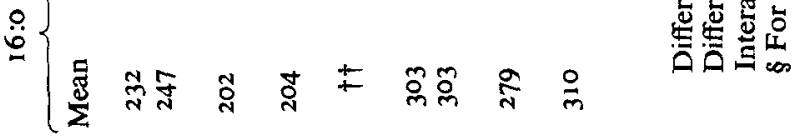

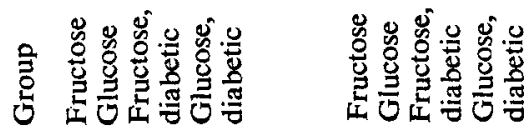

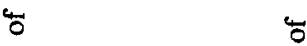

离等 
s.

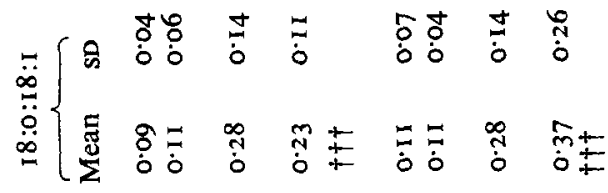

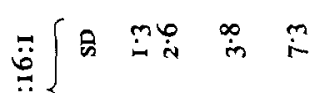

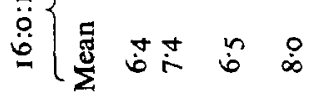

דั:

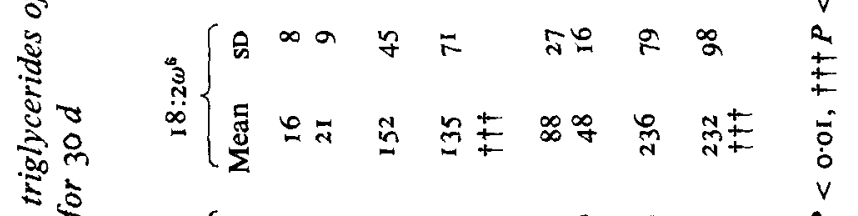

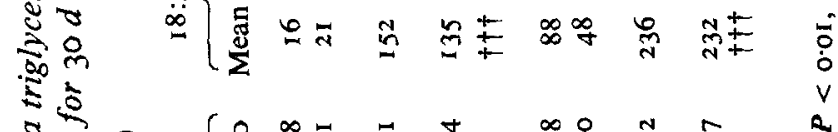

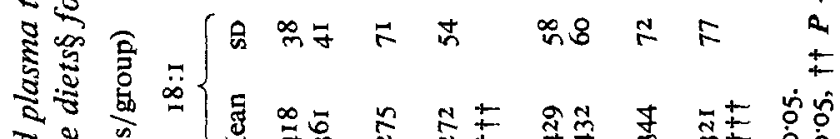

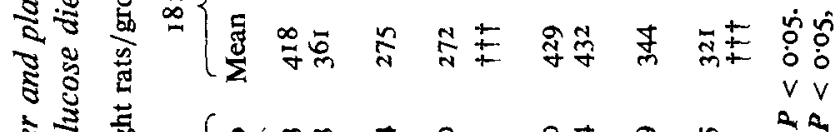

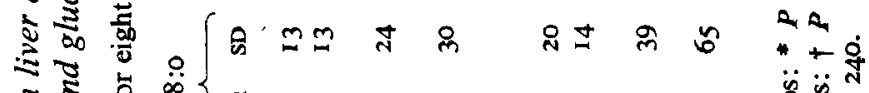

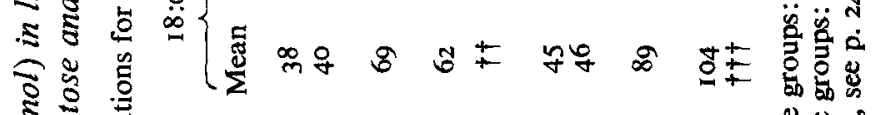

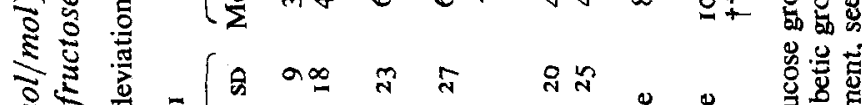

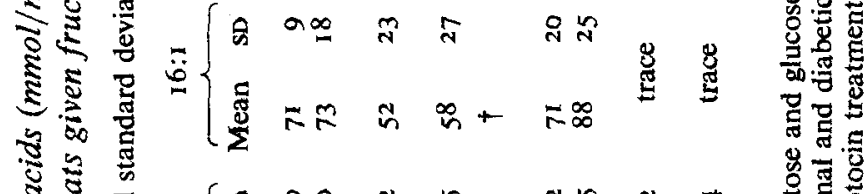

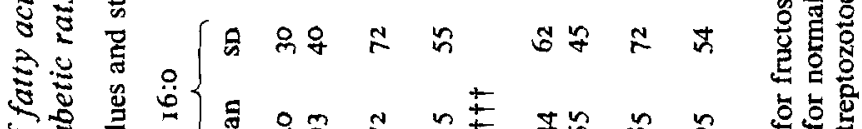

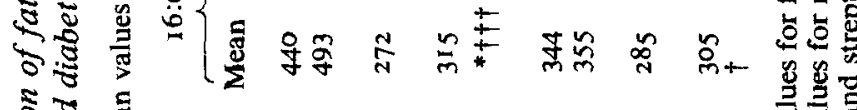

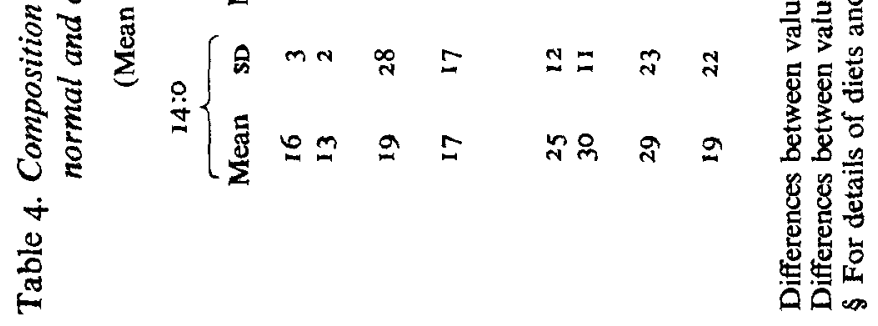

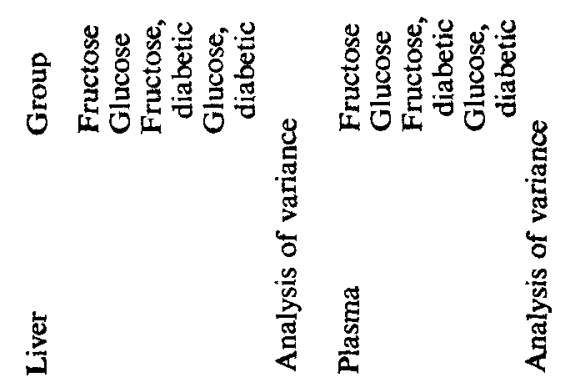




\section{Diet, diabetes and fatty acid desaturation}

acid content and to a less extent of arachidonic acid in the tissue lipids from rats fed on margarine (Tables 5 and 6). There was a concomitant change in the proportion of most other fatty acids, particularly oleic and stearic acids, thus giving a higher value for $18: 0:$ I $8:$ I in margarine fed animals. Where sufficient $16: 1$ was detectable, the presence of margarine in the diet also gave a higher value for $16: 0: 16: 1$, although the proportion of $16: 0$ of the total is only slightly different in the tissue lipids of rats in the four dietary groups.

There were also differences in the fatty acid composition of rats fed on different carbohydrates. The main change was a lower percentage of linoleic acid in the tissues of sucrose-fed animals (Tables 5 and 6). This was statistically significant by analysis of variance in the plasma phospholipids and liver triglycerides and in the cholesteryl ester fractions of liver and plasma (not shown). In other fractions, liver phospholipid and plasma triglyceride and total adipose tissue lipid, there was a significantly lower linoleic acid content in rats fed on sucrose and butter compared to those fed on starch and butter when a Student's $t$ test was used. In the presence of margarine the difference disappeared. Usually the difference between rats fed on sucrose or starch in linoleic acid content of tissue lipids was proportionally much greater than the small differences in the amount of this fatty acid in the diet. In most instances this decrease in linoleic acid was accompanied by an increase in oleic acid, but without a consistent change in the value of $18: 0: 18: 1$.

\section{DISCUSSION}

The assay system for stearoyl CoA desaturase proved to be reliable and reproducible, but there was some slight but linear variation in activity over a range of microsomal protein concentrations. In a recent study by Jeffcoat et al. (1976, 1977), in which a different assay system was used ( ${ }^{14} \mathrm{C}$-stearoyl CoA substrate), it was found that the presence of bovine serum albumin or a purified soluble liver protein was necessary for a linear relationship between enzyme activity and protein concentration; this occurred in the absence of these agents only when the microsomes are partially purified.

Our own study confirmed previous reports that the activity of stearoyl CoA desaturase depends on the nature of the dietary carbohydrate not only in short $3 \mathrm{~d}$ experiments (Mercuri et al. 1974) but also after feeding for longer periods when 'overshoot' effects should have subsided. The changes in desaturase activity were in general paralleled by those of fatty acid synthetase, but the differences due to changes in dietary carbohydrate on the latter enzyme were usually proportionally greater. In adipose tissue a diet with fructose produced lower desaturase activity than did a diet with glucose, but dietary sucrose produced the same activity as did dietary starch.

Rats made diabetic with streptozotocin and given fructose or glucose had lower liver desaturase and synthetase activity than normal animals, but the difference was less than that reported by other workers (Mercuri et al. 1974). This could be accounted for by the longer duration of our experiment, although the insulin levels of the diabetic animals were very low. Fructose restored the activity in diabetic animals to a value above that of the normal glucose group. As shown in earlier work (Bruckdorfer et al. 1972), only by combining the results of all groups could a significant correlation be found between fatty acid synthetase activity and plasma insulin. This was also true for stearoyl CoA desaturase activity. This suggests that control by insulin may occur only in rather extreme conditions and that the fine regulation of these enzymes must be controlled by other factors, possibly as a group (Jeffcoat, 1977).

The close similarity of the fatty acid composition of tissue lipids in rats fed on fructose and glucose suggests that the desaturation of saturated fatty acids is linked to their increased synthesis, especially in the liver, as concluded by Wahle (1974a). The relationship between fatty acid synthesis and desaturation was also apparent in genetically-obese rats fed 
NANCY A. WORCESTER AND OTHERS

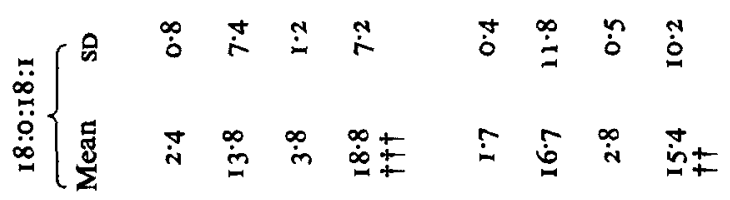

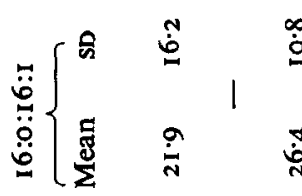

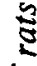

$b y$

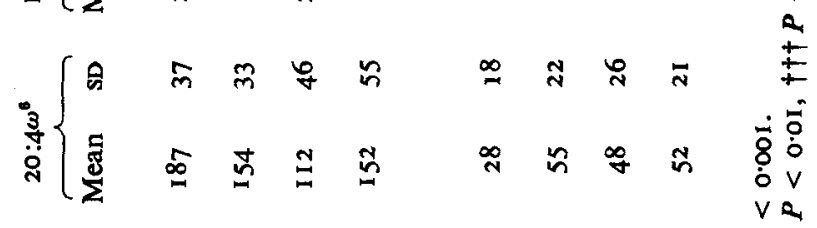

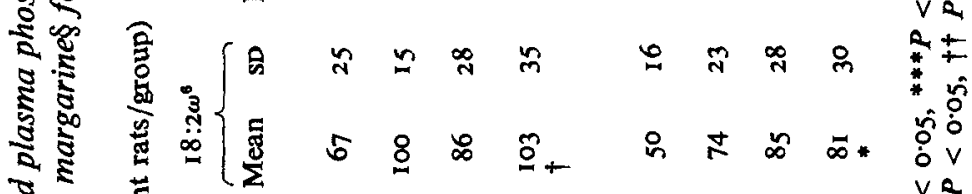

ह

के

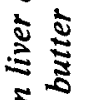

ㅇํㅇ

है

इ

हิ ล

ปั

ลे

है

S.

ธ

ปั้

ن

晜

苟 0 क

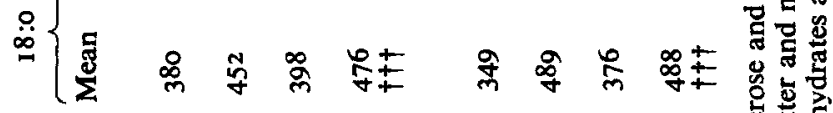

严 0

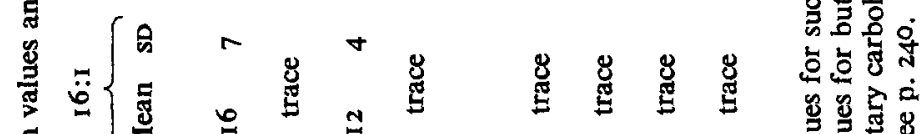

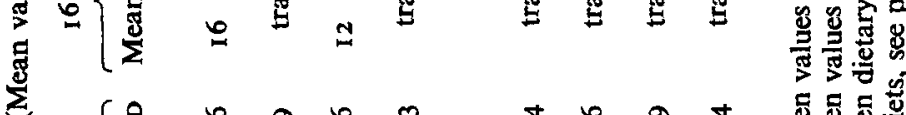

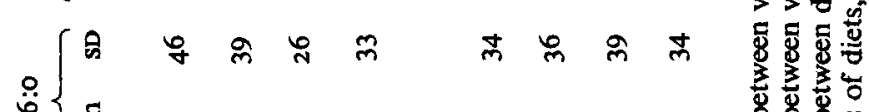

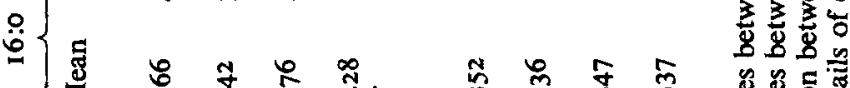
ไ

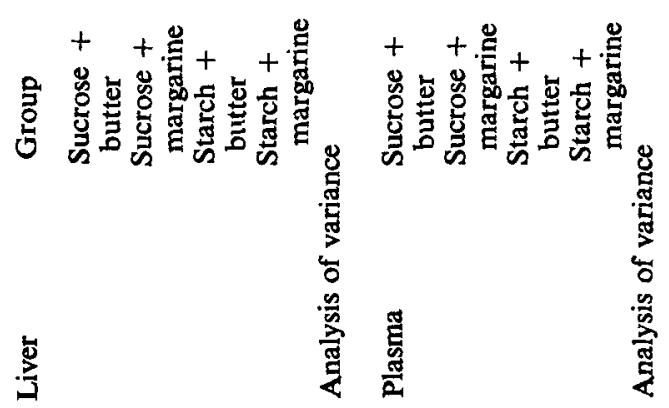


这

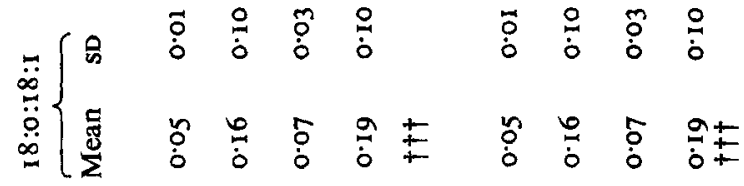

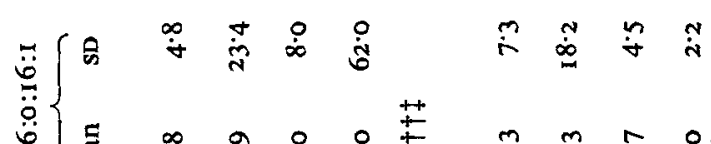

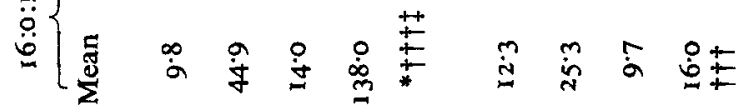

a

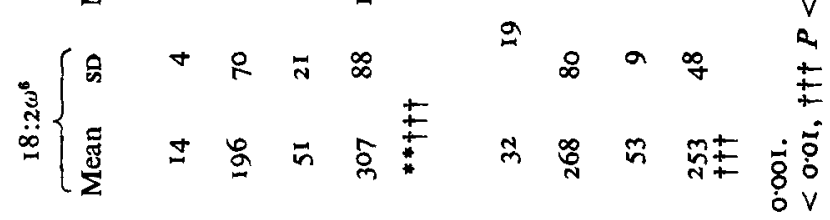

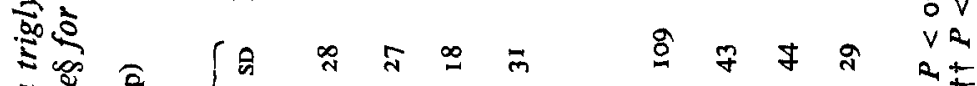

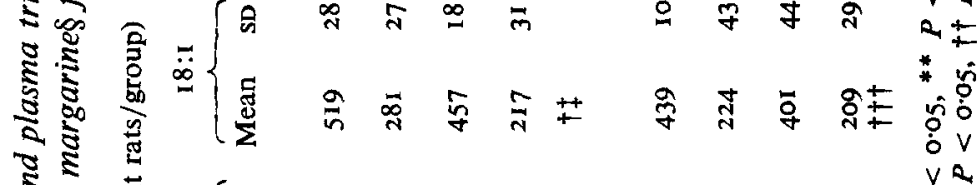

है

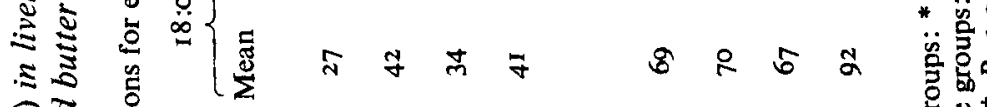

焉

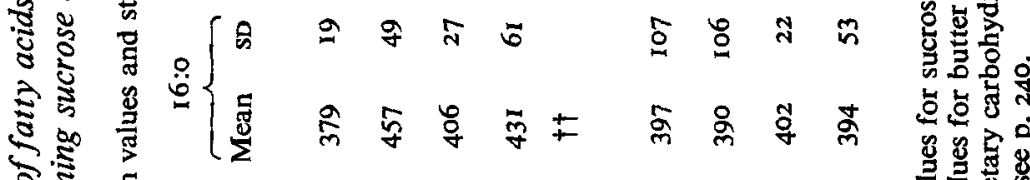

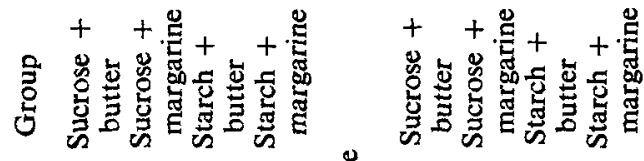

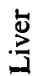

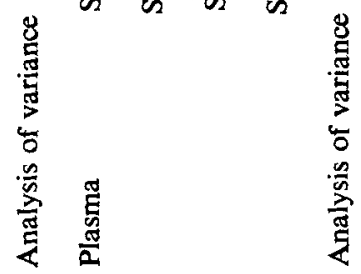


sunflower oil (Wahle \& Radcliffe, I977). In earlier studies, fructose was found to reduce the linoleic acid content of the lipids (Macdonald et al. 1975). The different results could have been due to differences in the compositions of the diets used in the two laboratories.

Long-term feeding on sucrose-rich diets, especially when accompanied by butter, led to a lower proportion of linoleic acid in tissue lipids compared to those fed starch; this has been noted in other animals and human subjects (Macdonald \& Braithwaite, 1964; Alling et al. 1973), but without a major change in the values for saturated:monounsaturated fatty acids. It is possible that the presence of large excesses of linoleic acid in the polyunsaturated margarine may mask, in some lipid fractions, the effect of sucrose that occurs when the supply of linoleic acid is more limited, as shown in experiments in which diets low in fats have been used (Bruckdorfer, unpublished results). The reduction in the percentage of linoleic acid may be the consequence of 'an increase in the hepatic synthesis of saturated and monounsaturated fatty acids in animals fed on sucrose or alternatively be an increase in linoleic acid oxidation. Increased endogenous synthesis of fatty acids was also thought to be the cause of the lower percentage of linoleic acid in the livers of obese Zucker rats compared to those found in their lean littermates (Wahle, I974b). The presence of large amounts of linoleic acid such as those provided in the margarine diet is thought to depress both fatty acid synthetase and stearoyl CoA desaturase activities (Jeffcoat \& James, 1977). The amount of arachidonate in the phospholipids was the same in animals fed on starch or sucrose; on the other hand, it was greater in those fed on margarine than in those fed on butter.

Although the linoleic acid content of maize starch is greater than that of sucrose, its contribution to the total diet is unlikely to have been enough to account for these effects of sucrose. In none of these tissues did significant quantities of trienoic acids arise to indicate an essential fatty acid deficiency. These findings may be of significance in human diets which are rich in both sucrose and animal fat, for which a synergistic action on lipid metabolism has been suggested (Antar et al. 1970).

The authors thank Miss L. A. Forrest and Mr J. Morrison for their excellent technical assistance.

\section{REFERENCES}

Alling, C., Cahlin, E. \& Schersten, T. (1973). Biochim. biophys. Acta 296, 518.

Antar, M. A., Little, J. A., Lucas, C., Buckley, G. C. \& Csima, A. (1970). Atherosclerosis I1, 191. Bruckdorfer, K. R., Khan, I. H. \& Yudkin, J. ( I972). Biochem J. 129, 439.

Christie, W. W. (1973). Lipid Analysis. Oxford: Pergamon Press.

Cohen, A. M., Briller, S. \& Shafrir, E. (1972). Biochim. biophys. Acta 279, I 29.

De Tomas, M. E., Peluffo, R. O. \& Mercuri, O. (1973). Biochim. biophys. Acta 306, 149.

Folch, J., Lees, M. \& Sloane-Stanley, G. M. (1957). J. biol. Chem. 226, 497.

Gellhorn, A. \& Benjamin, W. (1964). Biochim. biophys. Acta 84, 167.

Hales, C. N. \& Randle, P. J. (I963). Biochem. J. 88, I 37.

Inkpen, C. A., Harris, R. A. \& Quackenbush, F. W. ( 1969). J. Lipid Res. ro, 277.

Jeffcoat, R. (1977). Biochem. Soc. Trans. 5, 8I I.

Jeffcoat, R., Brawn, P. R. \& James, A. T. (1976). Biochim. biophys, Acta 43r, 33.

Jeffcoat, R., Brawn, P. R., Safford, R. \& James, A. T. (1977). Biochem. J. 161, 431.

Jeffcoat, R. \& James, A. T. (1977). Lipids 12, 569.

Johnson, A. R. \& Gurr, M. I. (197I). Lipids 6, 74.

Lowry, O. H., Rosebrough, N. J., Farr, A. L. \& Randell, R. J. (195I). J. biol. Chem. r93, 265.

Macdonald, I. (1962). J. Physiol., Lond. 162, 334.

Macdonald, I. \& Braithwaite, D. M. (I964). Clin. Sci. 27, 23.

Macdonald, I., Rebello, T. \& Keyser, A. (1975). Proc. Nutr. Soc. 34, 56A.

Mercuri, O., Peluffo, R. O. \& De Tomas, M. E. (1974). Biochim. biophys. Acta 369, 264.

Romsos, D. R. \& Leveille, G. A. (1974). Biochim, biophys. Acta 36o, I.

Skipski, V. P., Good, J. J., Barclay, M. \& Reggio, R. B. (1968). Biochim. biophys. Acta 152, 10.

Wahle, K. W. J. (1974a), Comp. Biochem. Physiol. 48B, 87.

Wahle, K. W. J. (1974b). Comp. Biochem. Physiol. 48B, 565.

Wahle, K. W. J. \& Radcliffe, J, D. (1977). Lipids 12, 135. 